\title{
Recidiva tardía de seminoma testicular en estadio I a los 11 años: tratamiento satisfactorio con quimioterapia sola
}

\author{
Late relapse of stage I testicular seminoma after 11 years: \\ successful treatment with chemotherapy alone
}

\section{Sr. Director:}

Alrededor del $45 \%$ de los tumores de células germinales son seminomas, que están presentes en estadio I en la mayoría de los pacientes.

La radioterapia, el tratamiento habitual tras la orquidectomía, origina una tasa de curación sin recidiva del 95\% y una tasa de curación global del 99-100\%. No obstante, debido al uso sistemático de radioterapia se trata innecesariamente a muchos pacientes, y la preocupación por los efectos clínicos a largo plazo de la irradiación ha llevado a una política de vigilancia de los varones en estadio clínico I.

Alrededor del 15-20\% de los pacientes sometidos a vigilancia sufrirán recidiva tras una mediana de 15 meses, aunque puede haber recidivas hasta 10 años después de la orquidectomía.

Las recidivas tardías de los tumores de células germinales (TCG) son infrecuentes. En esos casos se ha señalado que la quimioterapia sólo tiene un éxito modesto y que la cirugía puede ser la modalidad de tratamiento preferible.
En este informe se describe el caso de un varón con recidiva de un seminoma a los 11 años del diagnóstico inicial, en el que se logró una remisión completa con quimioterapia de rescate sola.

Un varón de 36 años acudió a consulta en septiembre de 1990 quejándose de una hinchazón dura del testículo derecho en el último mes, no dolorosa a la palpación. No se hallaron marcadores tumorales en el suero, y una tomografía computarizada (TC) no mostró anomalías en el tórax, el abdomen ni la pelvis.

El paciente eligió una estrategia de vigilancia intensiva durante 5 años tras la orquidectomía.

Se practicaron exploraciones físicas, análisis de marcadores tumorales en suero y radiografías de tórax cada mes durante un año tras la cirugía, cada dos meses durante el segundo año, cada 4 meses durante el tercer año y cada 6 meses durante el cuarto año. Se realizaron TC cada tres meses en el primer año postoperatorio, cada 4 meses durante el segundo año y en lo sucesivo sólo cuando estaban indicadas. 
El paciente permaneció libre de enfermedad hasta octubre de 2001, cuando apareció una linfadenectomía supraclavicular izquierda. Además, una TC reveló una masa retroperitoneal longitudinal de $9 \mathrm{~cm}$ adherida a la aorta abdominal, pero ninguna otra lesión.

El examen de una biopsia de los ganglios del cuello reveló la presencia de seminoma.

No se hallaron marcadores tumorales en el suero. Se trató al paciente con 4 ciclos de $20 \mathrm{mg} / \mathrm{m}^{2}$ de cisplatino por vía intravenosa a diario durante 5 días y $100 \mathrm{mg} / \mathrm{m}^{2}$ de ectopósido por vía intravenosa a diario durante 5 días, repetidos cada tres semanas.

Una nueva estadificación tras 4 ciclos de quimioterapia reveló una remisión completa.

El paciente seguía bien, sin recidiva, en el último seguimiento realizado en junio de 2009.

La introducción de la quimioterapia basada en cisplatino para el tratamiento de los TCG a finales de la década de 1970 mejoró espectacularmente los resultados obtenidos en pacientes con estas neoplasias.

Sin embargo, el $10-30 \%$ de los pacientes sufrirá una recidiva tras el tratamiento inicial. Estas suelen ocurrir en los dos primeros años siguientes al tratamiento, y en su mayoría se resuelven con terapia de rescate. Últimamente se ha hecho evidente que un número reducido de pacientes (alrededor del 1-4\%) sufren recidivas tardías ${ }^{1-5}$.

El lugar de asiento más frecuente de la recidiva es el retroperitoneo, aunque se han notificado recidivas tardías de TCG en el tórax, el cuello, la pelvis, el cerebro y el hígado3-4.

Baniel et $\mathrm{al}^{1}$ comunicaron que sólo se observó una respuesta completa en 17 de 65 (26\%) pacientes que recibieron quimioterapia, y sólo dos de estos pacientes se curaron con quimioterapia sola, mientras que 11 de 16 (69\%) tratados con cirugía sola permanecían libres de enfermedad tras una mediana de seguimiento de 14 meses. Los autores concluyeron que la cirugía es el tratamiento de elección, y de que la quimioterapia tiene un papel marginal en el tratamiento de la recidiva tardía.

En el análisis de Dieckmann et $\mathrm{al}^{6}$ se trató con quimioterapia sola al $46 \%$ de los pacientes, mientras que el 34\% recibieron tratamiento combinado (cirugía y quimioterapia). El 84\% de los sujetos logró una remisión completa tras el tratamiento.
Gerl et $\mathrm{al}^{2}$ revisaron 25 pacientes con recidiva tardía y comunicaron una tasa de supervivencia sin enfermedad del $36 \%$ tras una mediana de seguimiento de 38 meses. Un total de 20 varones se sometieron a quimioterapia para el tratamiento de la recidiva tardía.

La mayoría de las series muestran que la resección quirúrgica se asocia con mejoría del resultado, y con la quimioterapia sólo se comunican éxitos modestos.

Creemos que puede tratarse con quimioterapia a los pacientes que no la han recibido previamente, sin necesidad de practicar cirugía si se logra una remisión completa.

\section{B I B L I O G R A F Í A}

1. Baniel J, Foster RS, Gonin R, Donohue JP. Late relapse of testicular cancer. J Clin Oncol. 1995;13:1170-6.

2. Gerl A, Clemm C, Schmeller N, Hentrich M, Lamerz R, Wilmanns W. Late relapse of germ cell tumors after cisplatin-based chemotherapy. Ann Oncol. 1997; 8:41-7.

3. Shahidi M, Norman AR, Dearnaley DP, Nicholls J, Horwich A, Huddart RA. Late recurrence in 1,263 men with testicular germ cell tumors. Multivariate analysis of risk factors and complications for management. Cancer. 2002;95:520-30.

4. Oldenburg J, Alfsen GC, Waehre H, Fossa SD. Late recurrences of germ cell malignancies: a population-based experience over three decades. Br J Cancer. 2006;94:820-7.

5. George DW, Foster RS, Hromas RA, Robertson KA, Vance GH, Ulbright TM, et al. Update on late relapse of germ cell tumor: a clinical and molecular analysis. J Clin Oncol. 2003;21: 113-22.

6. Dieckmann KP, Albers P, Classen J, De Wit M, Pichlmeier U, Rick O, et al. Late relapse of testicular germ cell neoplasms: A descriptive analysis of 122 cases. J Urol. 2005;173:824-9.

B. Detti*, S. Cipressi, V. Di Cataldo y G. Biti Instituto de Radioterapia, Universidad de Florencia, Italia

*Autor para correspondencia Correo electrónico: b.detti@dfc.unifi.it (B. Detti). 